\title{
Digital Empowerment - A Need for Strengthening Teachers' Role
}

\author{
Dr. Dimple Bhalla \\ Assistant Professor, Department of Education \\ G. S. College of Commerce \& Economics, Autonomous, Jabalpur (M.P.)
}

\begin{abstract}
Digital Literacy i.e. the ability to locate, organize, understand, evaluate and create information using information and communication technology, has become an inseparable part of education system. Today's condition arose due to COVID-19 crisis demands teachers to play a significant role in motivating students to pursue self-directed learning. Digitalization is the only means to bridge the gap between learners and their learning goals. The objective of present study is to evaluate the digital literacy among teachers and to study effect of digitalization on educational process during COVID-19. Study conducted is both Analytical and Descriptive in nature. Online survey has been conducted to collect the data. Sample of 50 teachers are selected by random sampling technique from schools and colleges of Jabalpur District. A self-made questionnaire carrying 15 items and secondary data is used as a tool to evaluate the digital literacy among teachers and to study the effect of digitalization on educational process during COVID-19. Based on analysis, suggestions have been given to upgrade the concept of online education which is the need of an hour.
\end{abstract}

Key words: Digital Literacy; COVID-19; Self-directed learning; Digitalization

\section{INTRODUCTION}

The Novel Coronavirus Disease 2019 (COVID-19) has originated in Wuhan City in China, has spread rapidly around the world, sending billions of people of different countries into lockdown. The World Health Organization declared the Coronavirus disease a pandemic. In light of rising issue associated with COVID-19 pandemic, great impact is seen on the education system and as a result of this mental health of students is also affected.

WHO declared that virus had spread to more than 177 countries around the world. Due to the incurable disease, many steps have been taken by the countries to prevent the spread of the disease. Firstly, countries have started restricting people from travelling (inwards and outwards) movements. Public Health experts and government have taken several measures for the safety of the people of the country including social distancing, self-isolation, quarantine etc. Health facilities are strengthened to fight against the disease. Places of social gathering get closed like shopping malls, gym, movie theatres, clubs etc. Even government declared closure of schools and colleges to reduce spread of infectious disease in the community. This is a crucial time for the education sector as board examinations and college examination, school and college admissions, entrance tests of various universities and competitive examinations etc. are all held during this period. As the days pass by, the structure of schooling and learning, including teaching and assessment methodologies, was the first to be affected by these closures. Only a handful of private schools could adopt online teaching methods. The primary challenge in the time of the crisis is to integrate and streamline digital infrastructure at various stages of Education.

\section{STATUS OF EDUCATION SYSTEM IN INDIA DURING COVID-19}

In education system, major transition with respect to teaching-learning process has been observed to overcome challenges caused due to COVID-19 pandemic i.e. face to face interaction with students in classroom has switched to online learning. Although, we are practicing digital mode of teaching learning from very long but still we are facing challenges like unavailability of smart phones and internet with the students of rural areas. Due to the present crisis we never had in our dream, schools and universities have to suspend their final exams immediately. As use of technology for conducting final exams has not yet been developed so far, students are under great stress because of uncertainty with respect to their future. But still the power of technology cannot be denied. With approximately 131 million cellular-phone households in the country, we believe that delivering education through the digital platform to children and teachers could be a potential way to bridge the education deficit during this adverse situation arose due to COVID-19. However, the challenge has always been how the technology will get adopted to make a significant difference. With the various digital initiatives that the government has launched, we are hopeful that it will help strengthen access to technology especially in government schools and and colleges which will in turn help us to fight this situation out. To beat the lockdown blues, government's initiative of Digital Infrastructure for Knowledge Sharing (DIKSHA) has given a new dimension to the relations between students and teachers.

According to a study conducted, growth drivers of online education in India are-

- Online education provides the low cost alternative to the students.

- Online education provides quality education to potential learners.

- Government initiative such as SWAYAM, E-Basta, Rashtriya Madhyamik Shiksha Abhiyan (RMSA), Skill India and Digital India will enables the infrastructure needed by students to adopt online education.

- Internet penetration in semi-urban and rural areas, witnessed exponential growth in online education across India.

- Growing Smartphone penetration across India reflects adoption of technology by learners in India. 
- Young population with higher expectation and lower income is a good target market for online education.

According to AISHE report 2018-2019, Distance education has become a useful mode of obtaining degrees for a large number of students who are staying in far off and remote areas and for whom accessing universities on regular basis is still a dream. Distance enrolment constitutes $10.62 \%$ of the total enrolment in higher education, of which $44.12 \%$ are female students. At Post Graduate, Under Graduate, PG Diploma, Diploma, Certificate level share of distance enrolment in university is $28.8 \%$, $77.8 \%$, $2.9 \%, 3.7 \%$ and $1.23 \%$ respectively. The above data reveals the fact that online learning has become a popular mode of learning especially for students of higher Education.

\section{EFFECT OF DIGITALIZATION ON EDUCATION DURING COVID-19 CRISIS}

The COVID-19 crisis has changed our world and our global outlook and taught us about how education needs to change to be able to better prepare our young learners for what the future might hold. In the words of Winston Churchill, "A pessimist sees the difficulty in every opportunity; an optimist sees the opportunity in every difficulty."

Governmental agencies and other organizations are contributing to the effort to transition schools to more connected teaching strategies. With digitization, schools and universities can provide a new phase of learning with various advanced techniques:

\section{- Online courses}

Online courses are provided by experts online who have excellent proficiency in their specific field and they offer the experience of real-time learning to their students by designing their own online courses.

\section{- Digital textbooks}

With digitization, there are several e-textbooks and e-texts, digital textbooks available that provide an interactive interface in which students can access to multimedia content like videos, interactive presentations, and hyperlinks.

- Online exams

Digitization allows students to give online exam. This makes the examination process convenient for both teachers and students.

Digitization of education thus helps to improve the quality of education by encouraging self- study, ensuring better understanding and providing access to education.

The COVID-19 crisis enforces the following changes in education -

- $\quad$ Preparing learner based on global needs.

COVID-19 pandemic illustrated how globally interconnected. Educationist need to understand this interrelatedness and prepare learners in a globally collaborative way so that they can be prepared for future in an effective manner.

- $\quad$ Redefining the role of the teacher and learner

The role of teacher to impart knowledge to their pupils is no longer fit for accomplishing the objectives of a 21 st-century education. Students being able to gain access to knowledge, and can even learn a technical skill by their own, through a few clicks on their phones, tablets and computers, we need to rethink on role of teacher which could be a facilitator and learner as active participant.

- Life skills as important part of curriculum

Essential skills that contribute to the development of resilience and adaptability to navigate effectively through this pandemic should be developed in the learners. Other most important skills that learner must possess is creativity, communication and collaboration, along with empathy and emotional intelligence for teamwork.

- Unblocking technology to deliver education for all

The COVID-19 pandemic forced all educational institutions across the world to utilize the suite of available technological tools of teaching-learning for students in all sectors. Educators across the world are experiencing new possibilities with respect to pedagogy of online teaching to benefit their students as far as possible.

\section{REVIEW OF LITERATURE}

Dua, Shikha; Wadhawan, Seema, Gupta, Sweety; (2016); Issues, Trends \& Challenges of Digital Education: An Empowerment Innovative Classroom Model for Learning www.conferenceworld.in, ISBN: 978-81-932074-8-2; The objective of this paper is to discuss the upcoming trends in digital education system, which shapes the future of young generation towards empowerment. To resolve the shortcomings of the traditional education system, the world is moving towards digital education which addresses all the issues and challenges of traditional education. The authors feels that digital education can be defined as the use of a combination of technology, digital content and instruction in the education system to make it more effective and efficient than the traditional education system.

Dr. Thah, Soon, Seng; (2013); Digital empowerment in education for school administrators and teachers - The Malaysian experience; This study aims at exploring the need for Digital education from Pre-school to Post-secondary education and another higher study. The author opines that Digital empowerment depends on the systematic plan and its implementation in educational institutions where it can be measured by the level of teacher teaching and student learning. The author also states not only students and teachers; parents should also take active part and support their children to excel in this field.

Akkoyunlu, Buket, Yilmaz ; (2011); Prospective Teachers' Digital Empowerment and Their Information Literacy Self-Efficacy; Eurasian Journal of Educational Research (EJER) 11(44):33-50; The purpose of the study is to determine the prospective 
teachers' digital empowerment and their information literacy self-efficacy. Methods: Descriptive survey research was designed to search prospective teachers' digital empowerment and their self-efficacy beliefs about information literacy. Result showed that prospective teachers' self-efficacy beliefs on the interpreting, synthesizing \& using the information and evaluating the product and process and their digital empowerment on the empowerment are not fully satisfactory. Based on our findings, it is recommended to develop and maintain information literacy and digital empowerment programs for prospective teachers. Which are vital for lifelong learning? Besides, government's policies should give big importance to diffusion of information literacy and digital empowerment in schools and in the society.

Shenoy, Veena, Mahendher, Sheetal, Vijay, Navita; (2020); COVID 19 Lockdown Technology Adaption, Teaching, Learning, Students Engagement and Faculty Experience; Mukt Shabd Journal, Volume IX, Issue IV, APRIL/2020, ISSN No : 2347-3150. The purpose of this paper is to understand the technology adoption, teaching and learning process, student engagement and faculty experience towards virtual classrooms during Lockdown due to COVID 19. The finding of the study suggests that during the lockdown period faculty have undergone the process of technology adoption and students are involved with various online modes of learning. There was lots of fear, anxiety and consciousness among students and faculty regarding COVID 19. This study is confined to the positive side of COVID 19 and change in the education sector by adapting to technology and engaging students with various virtual sessions.

\section{OBJECTIVES}

- To evaluate the digital literacy among teachers.

- To study the effect of digitalization on educational process during COVID-19.

- To provide suggestions to increase teachers' efficiency to achieve learning outcomes.

\section{RESEARCH METHODOLOGY}

Study conducted is both Analytical and descriptive in nature based. Online survey has been conducted to collect the data. Sample of 50 teachers are selected randomly by random sampling technique from schools and colleges of Jabalpur District. A self-made questionnaire carrying 15 items and secondary data is used as a tool to evaluate the digital literacy among teachers and to study the effect of digitalization on educational process during COVID-19.

\subsection{Population \& Sample}

50 teachers from different Schools \& Colleges of Jabalpur district irrespective of their discipline is selected randomly using random sampling method.

\subsection{Data \& Sources of Data}

Primary and secondary data is used in the present study for the analysis of digital literacy seen among teachers and providing suggestions for improving its quality to achieve learning outcomes more accurately.

\subsection{Theoretical Framework}

The researcher used 15 questions to know the present status of teacher's knowledge about online education. The questions asked by the researcher is the independent variable whereas the response given by the teachers are dependent variables which are also affected by the intervening variables which includes instructions given by administrator of their school or college, teaching \& learning environment, availability of internet $\&$ smart device, experience of teachers working on computers.

\subsection{Statistical Tools}

Analysis is based on percentage of responses received by the researcher for the 15 questions asked

\subsection{Limitations}

- $\quad$ Data is collected online due to maintain social distancing.

- $\quad 50$ teachers are randomly selected from schools and colleges irrespective of their discipline. Study is restricted to Jabalpur district only.

\section{FINDINGS}

Following questions have been asked from the sample during survey to collect the data

1. Number of teachers using Online Education before COVID-19 crisis 


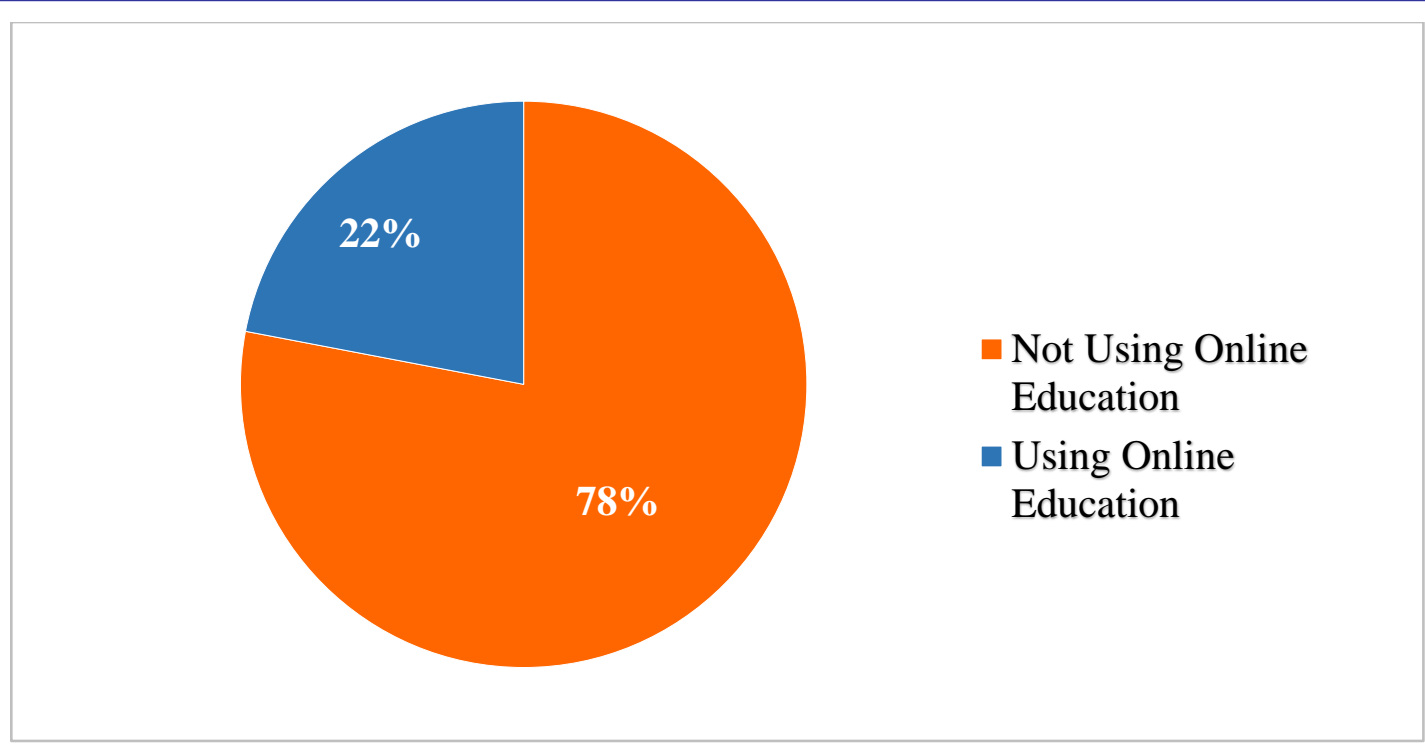

Graph $4.1 \%$ of teachers using online education before COVID-19

2. Number of teachers well acquainted to Digital Teaching Techniques

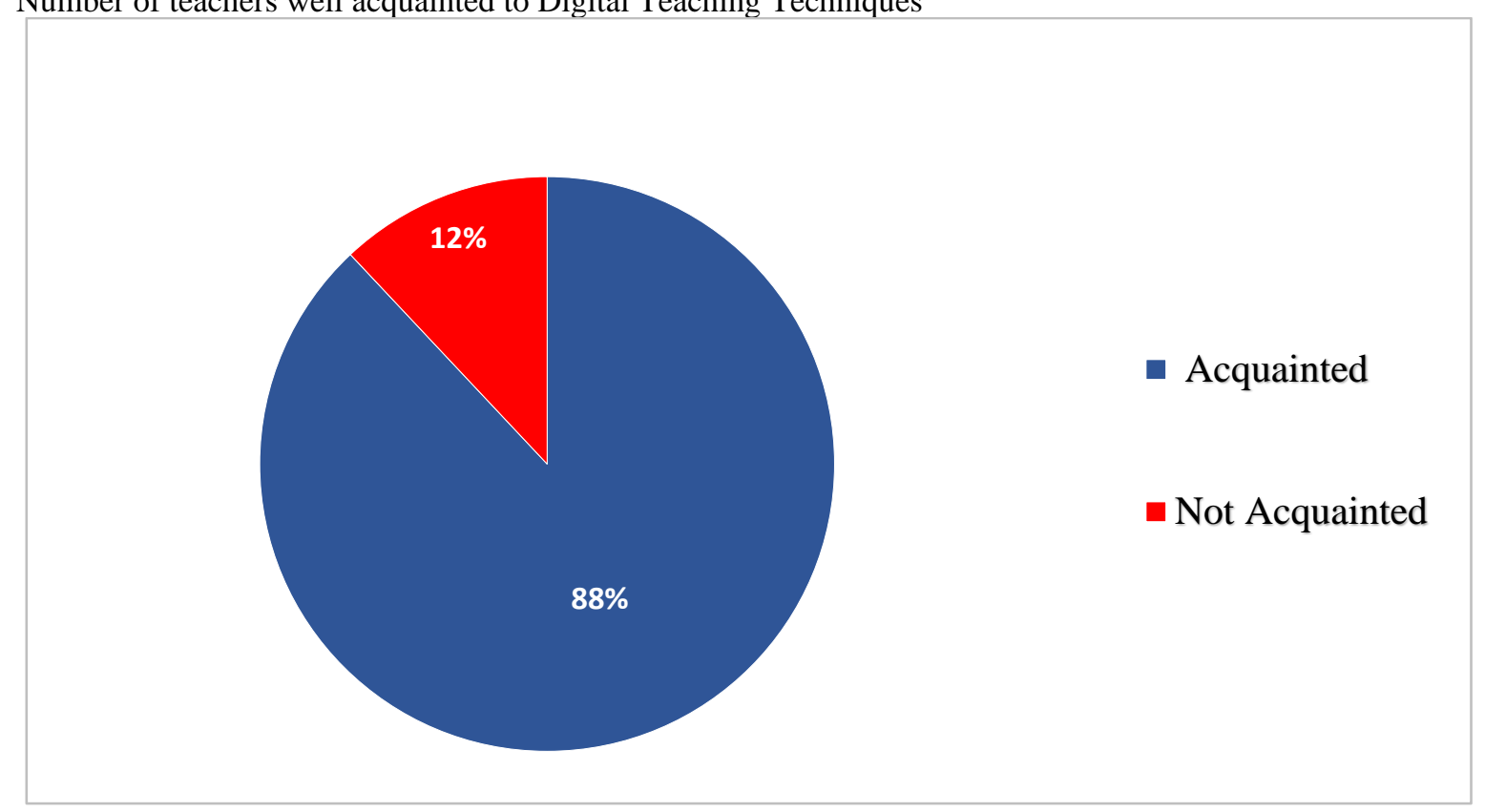

Graph $4.2 \%$ of teachers acquainted to digital teaching technique 
3. Key barriers faced by teachers in Offline Education.

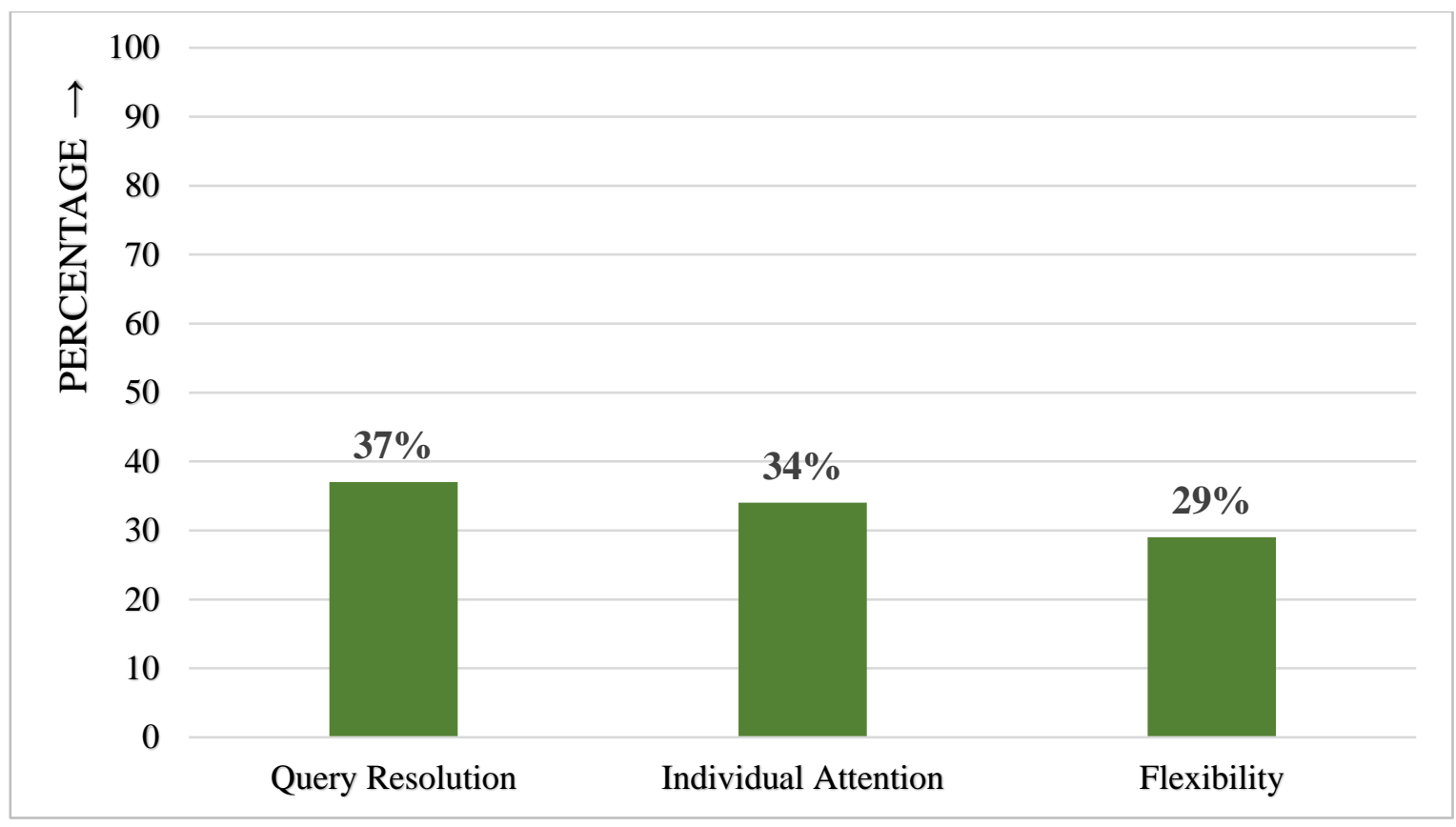

Graph $4.3 \%$ key barriers faced by teachers in offline education

4. Motivation factor forcing teachers to adopt Online Education

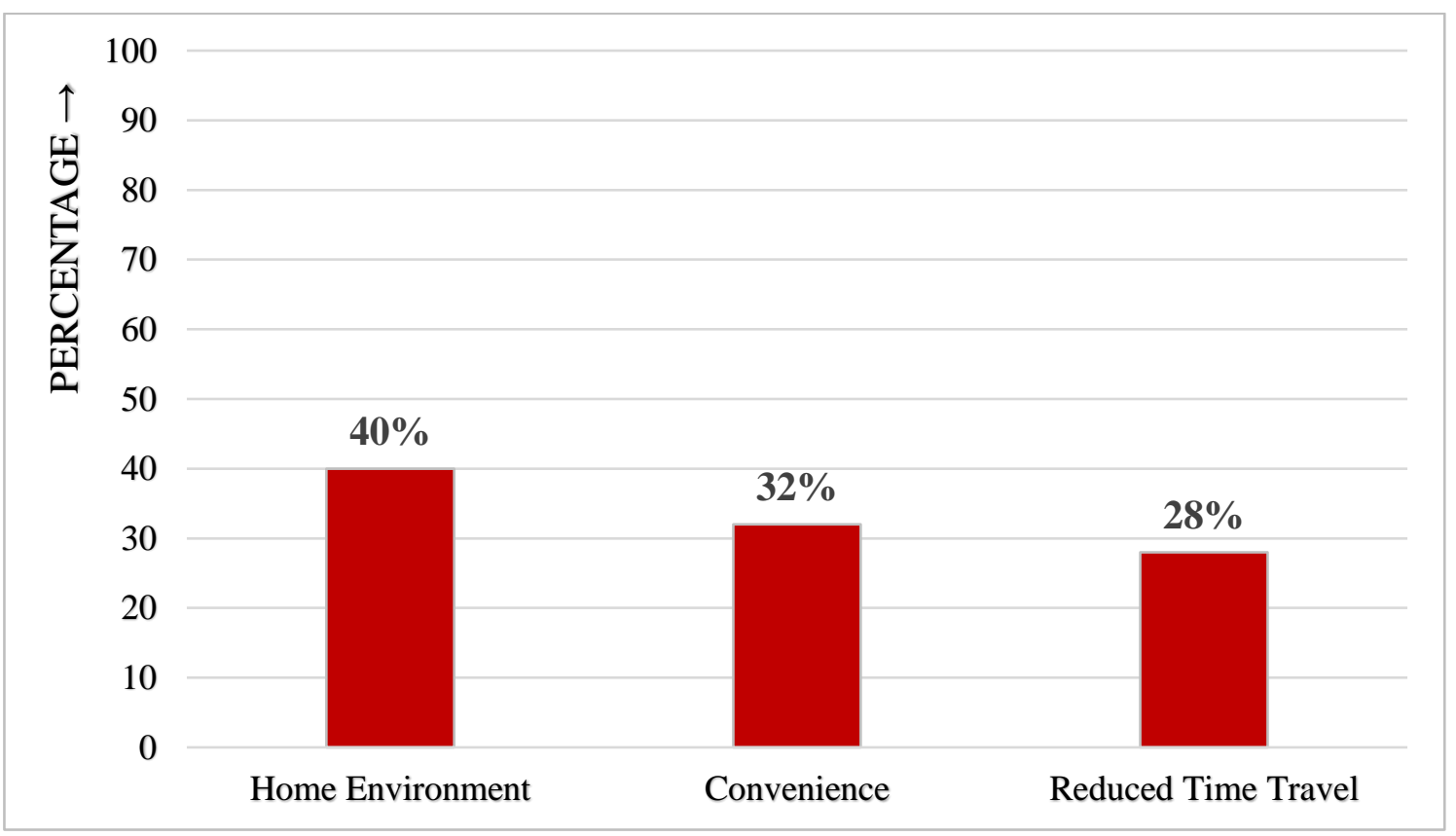

Graph $4.4 \%$ of motivational factor forcing teachers to adopt online education 
5. Foremost requirement for online teaching (apart from internet connectivity)

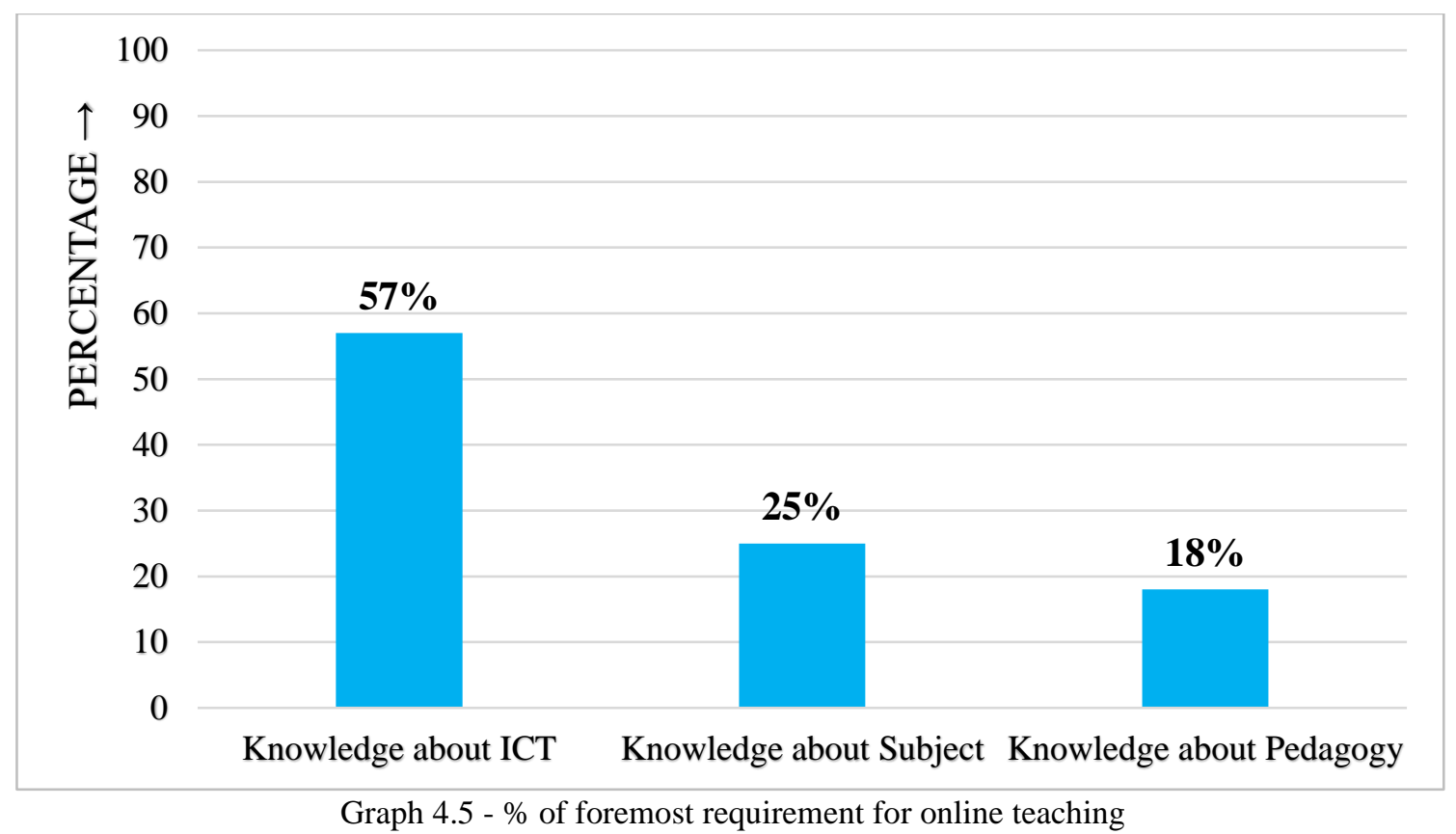

6. Teaching techniques used by teachers during lockdown due to Covid-19

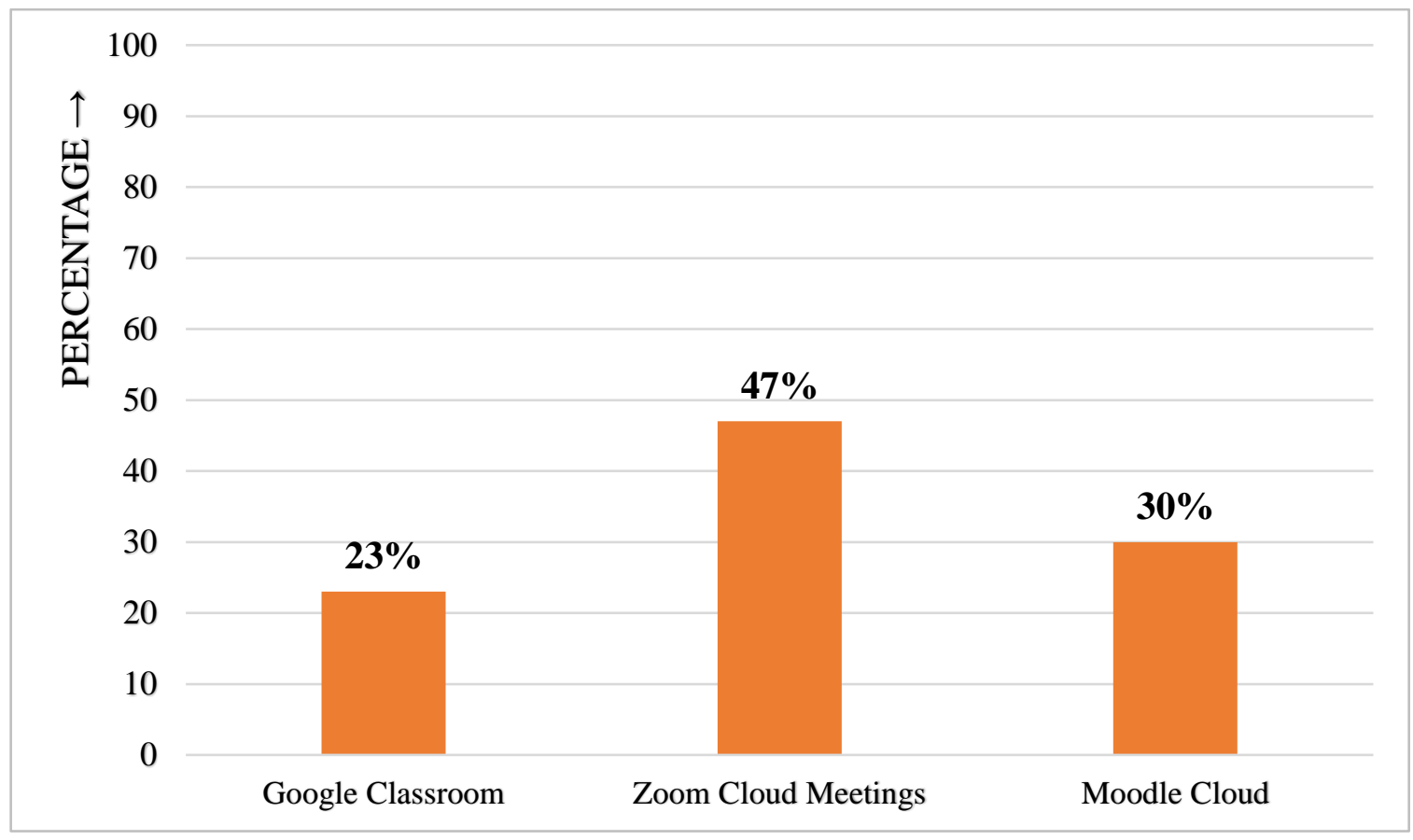

Graph 4.6 - \% of teaching techniques used by teachers during lockdown 
7. Most Convenient approach of Online Teaching for teachers.

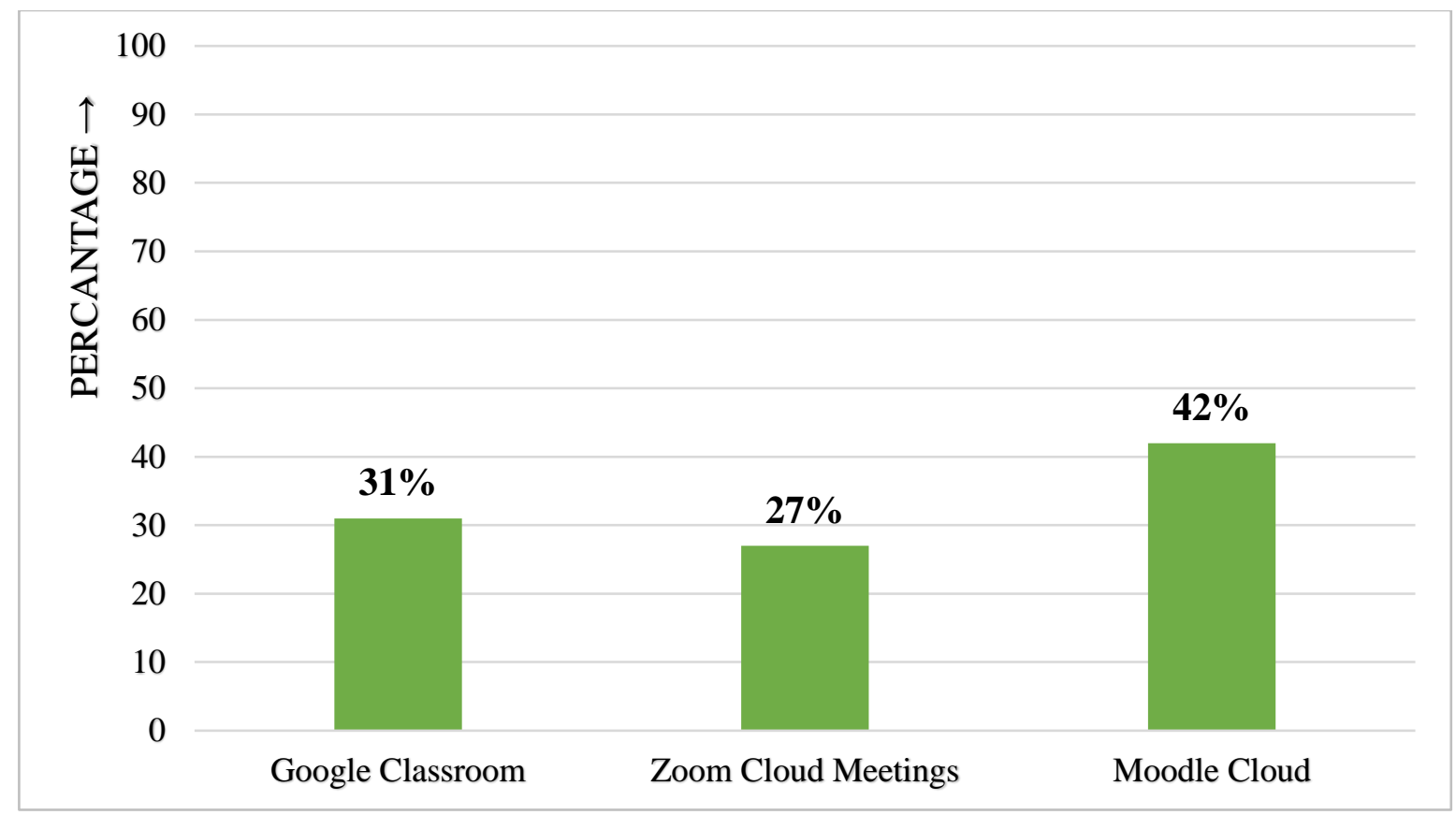

Graph 4.7 - \% of most convenient approach of online teaching for teachers

8. Expectation of Students from Online Education ( from teachers point of view)

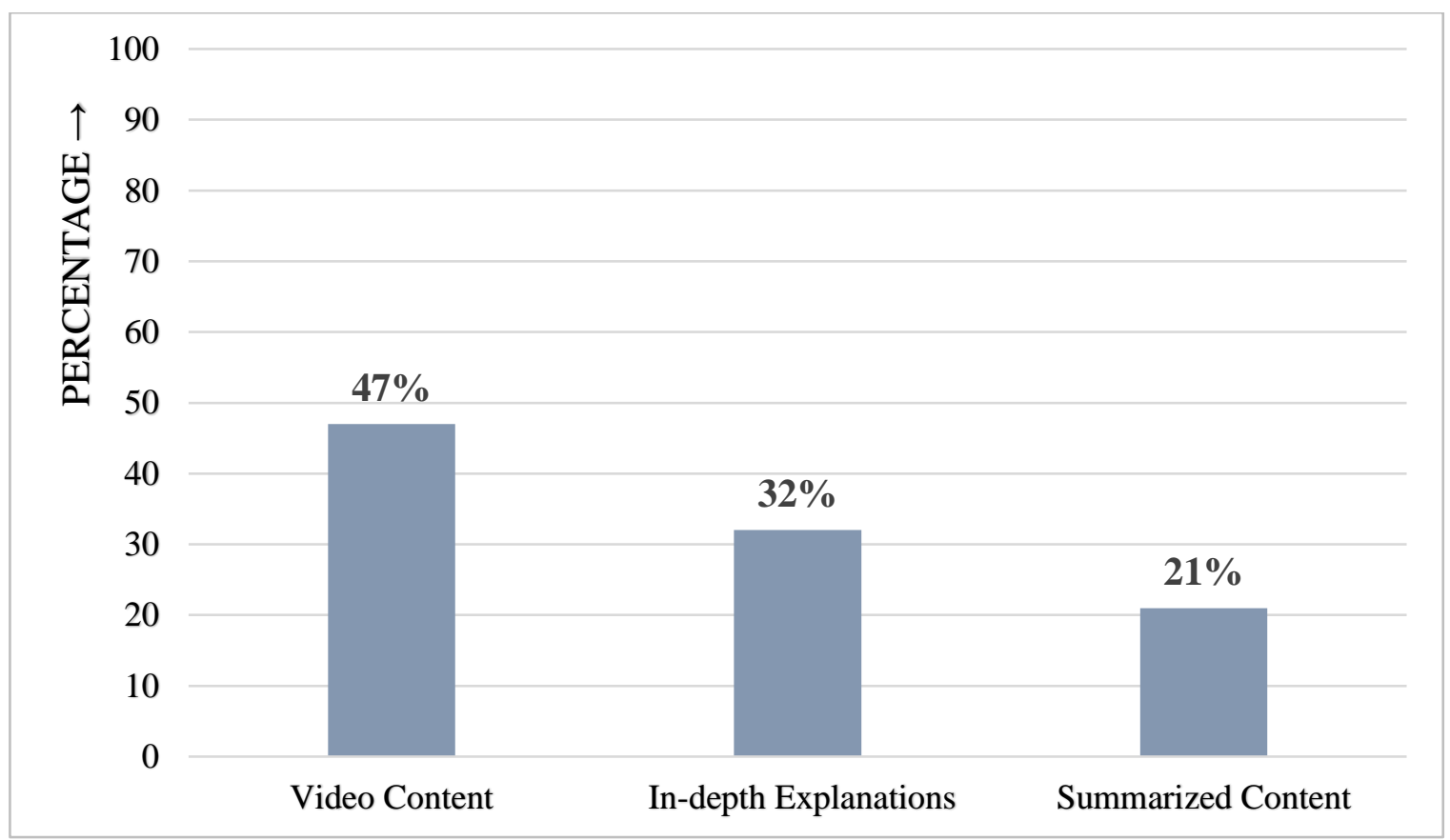

Graph 4.8 - \% of expectation of students from online education 
9. Barriers in students participation in online education (from teachers point of view)

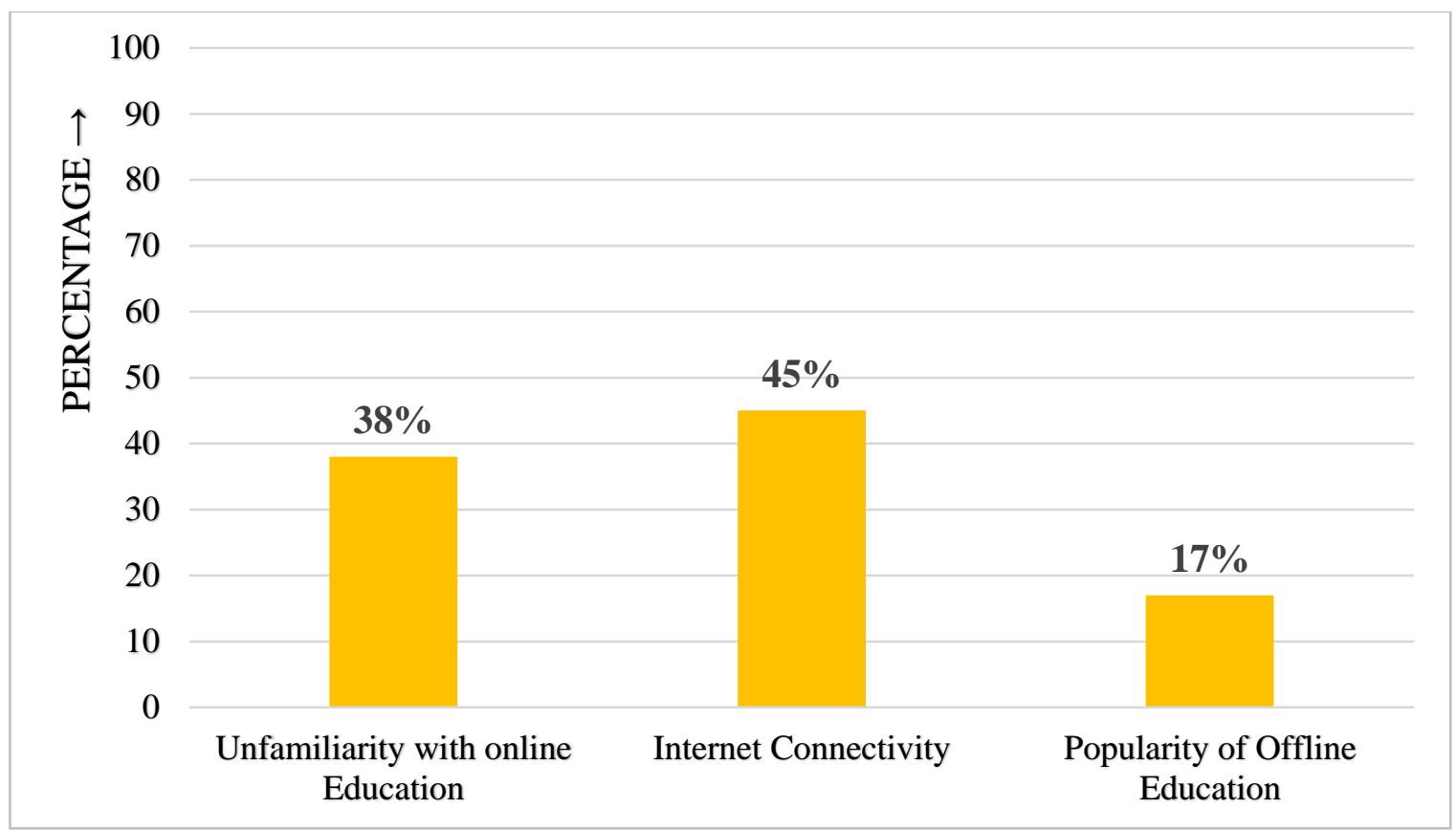

Graph 4.9 - \% of barriers in students' participation in online teaching

10. Source of study material for teachers' preparation (for online teaching) during present crisis

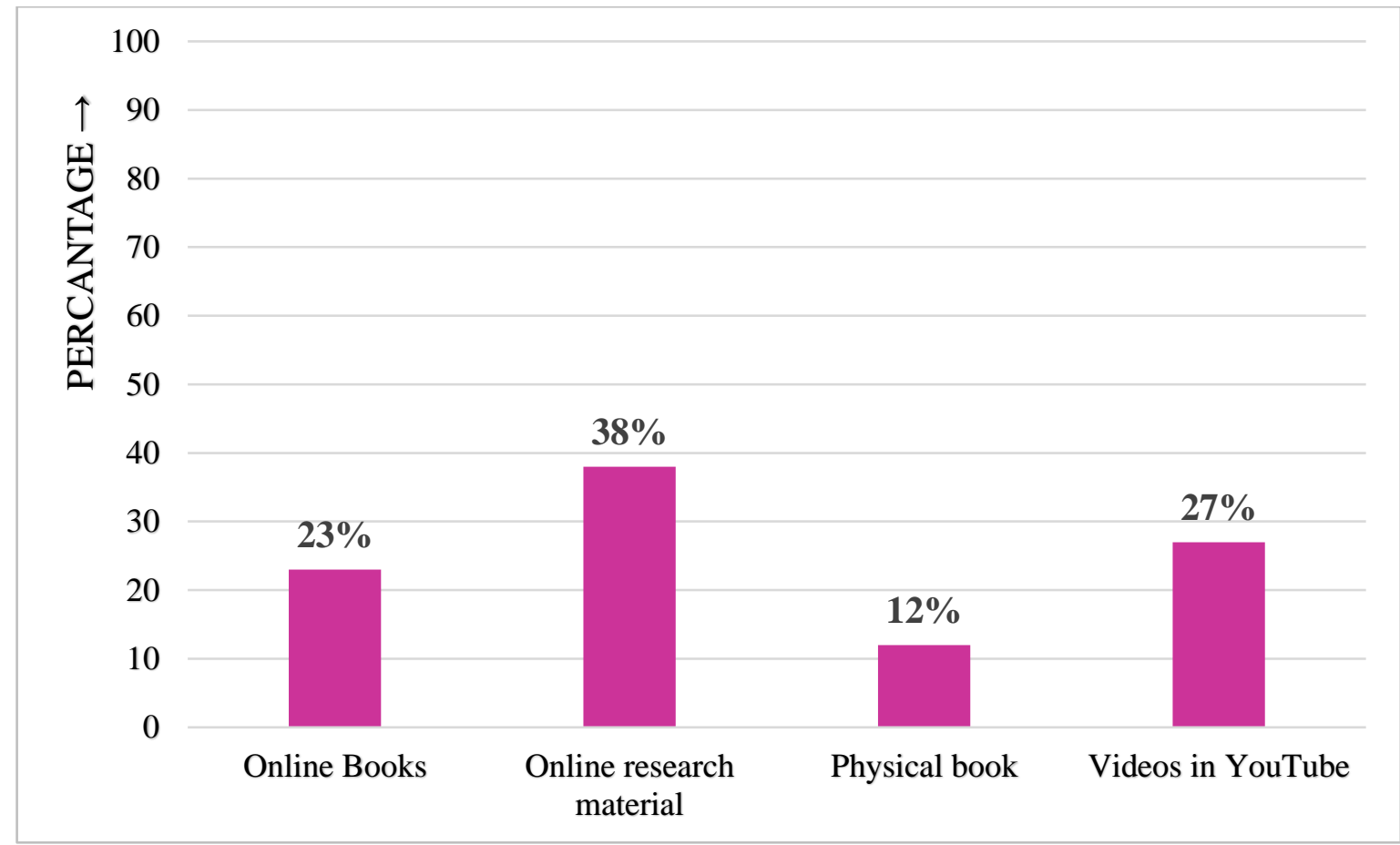

Graph 4.10 - \% of source of study material used by teachers for preparation 
11. Modern day students interest in acquiring knowledge

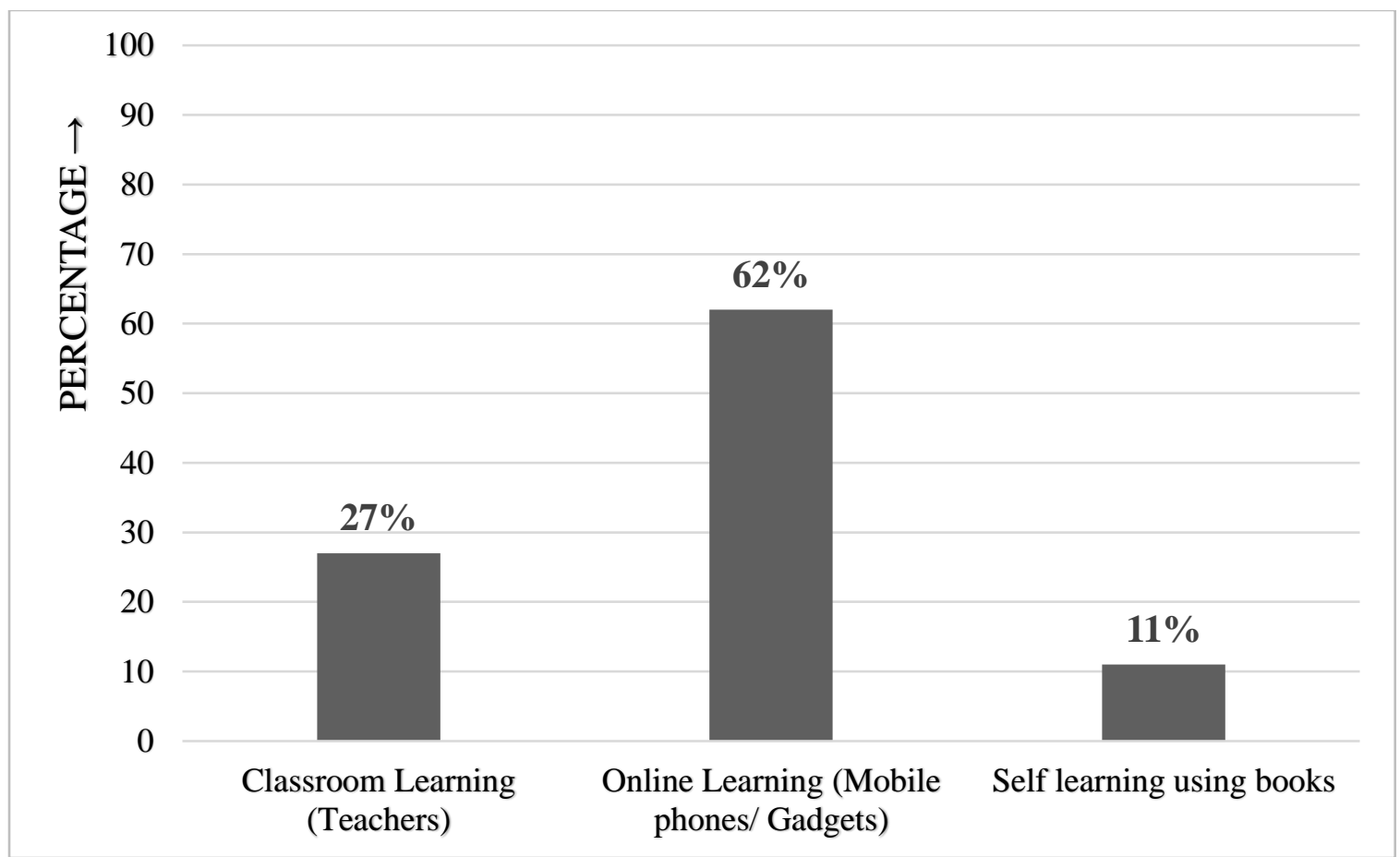

Graph 4.11 - \% of Modern day students interest in acquiring knowledge

12. Available Opportunities for teachers during Covid-19

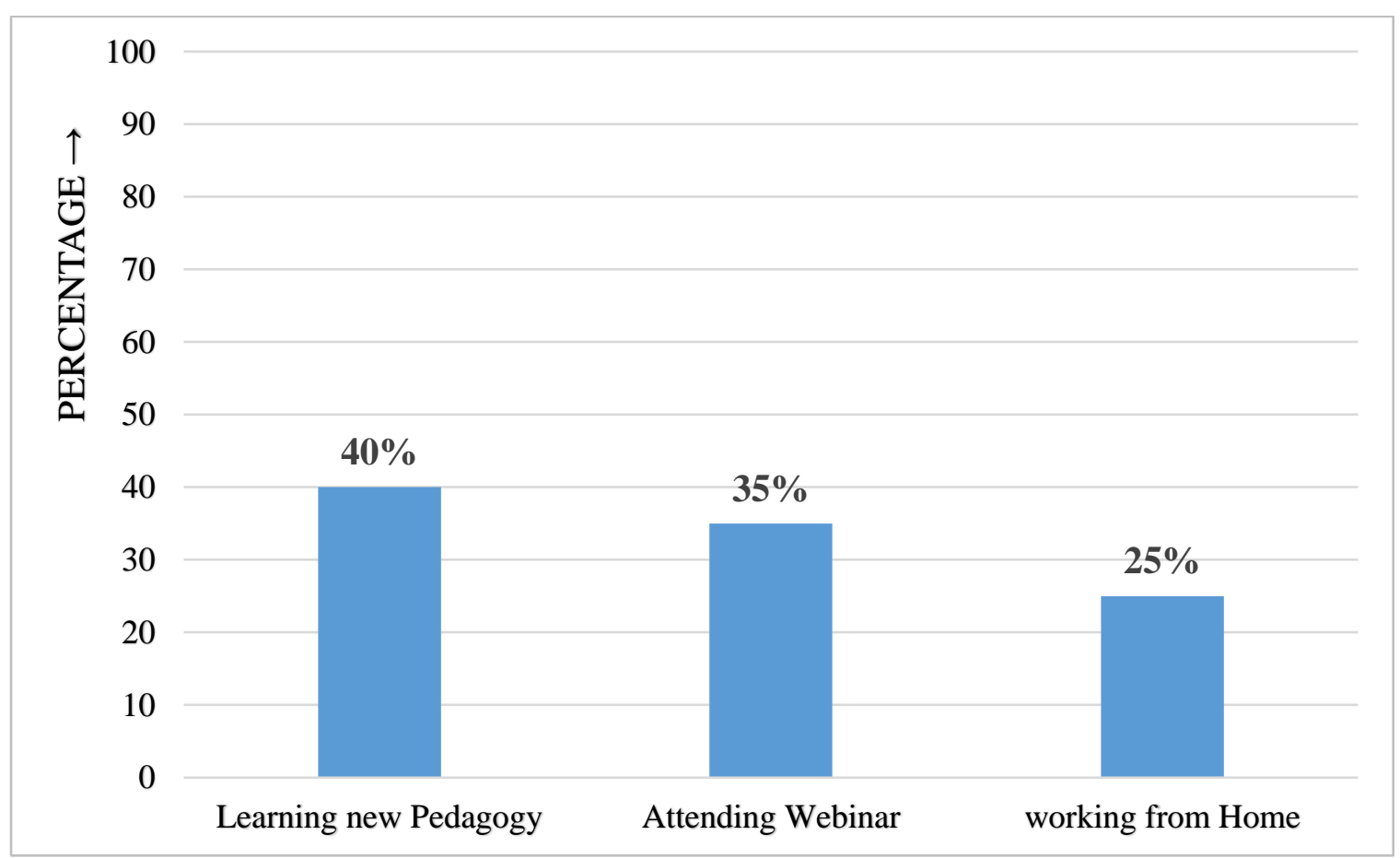

Graph 4.12 - \% of opportunities available for teachers during COVID-19 
13. Major problem associated with Education during Covid-19

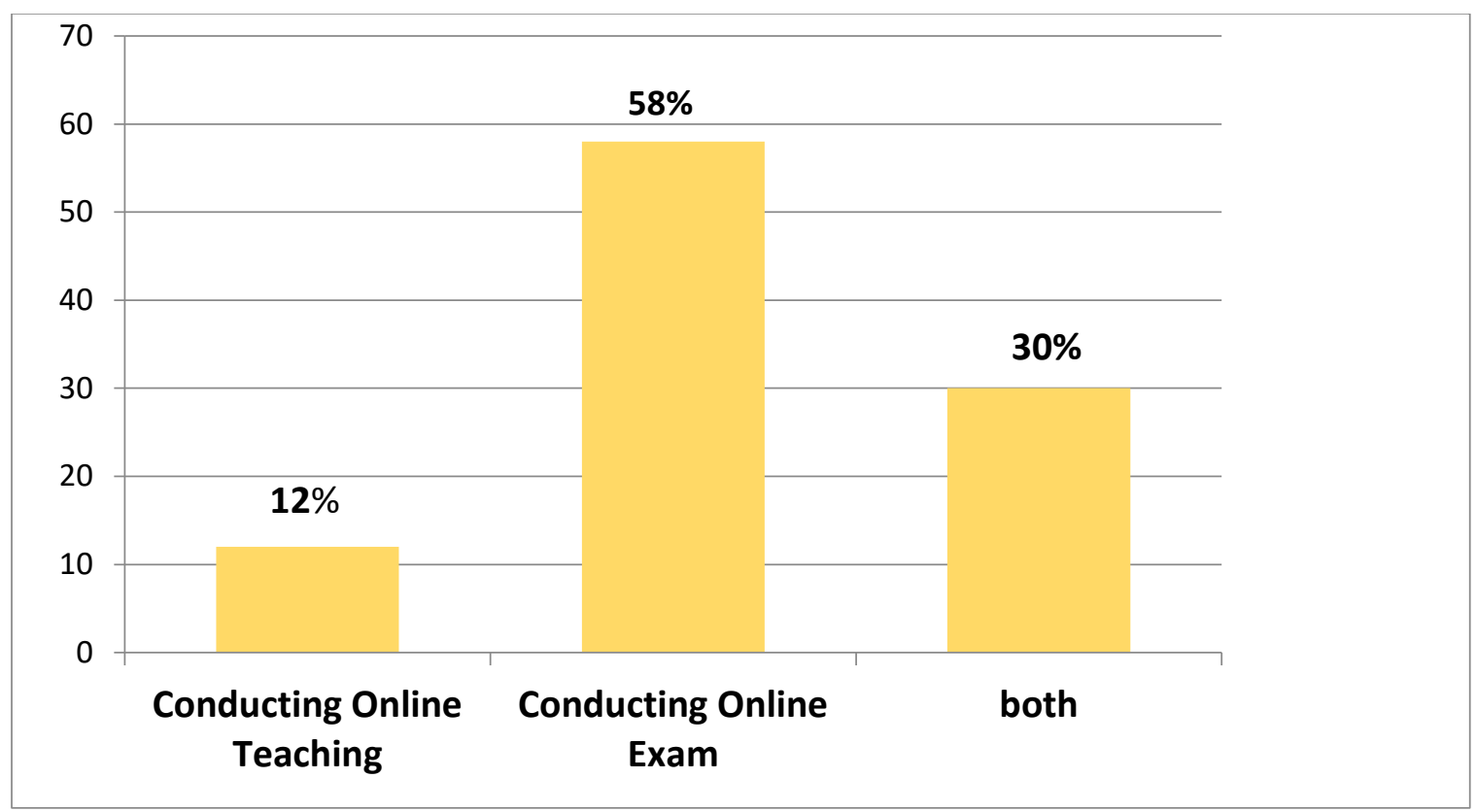

Graph 4.13 - \% of major problem associated with education during COVID-19

14. Teachers having knowledge about MOOC's and Digitally Robust Campus

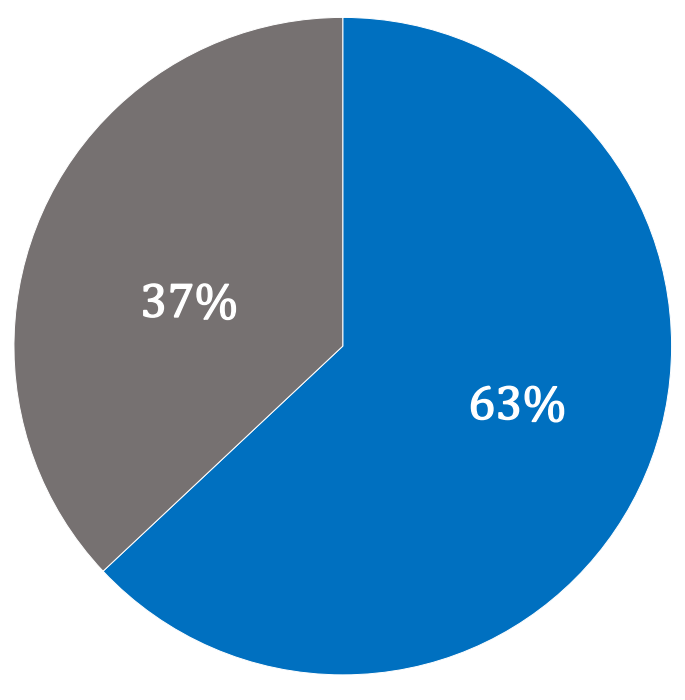

- Have Knowledge

Don't have

Knowledge

Graph 4.14 - \% of teachers having knowledge about MOOC's \& digital robust campus 
15. Teachers having membership of e-Library/ e-Journals/ e-Magazines

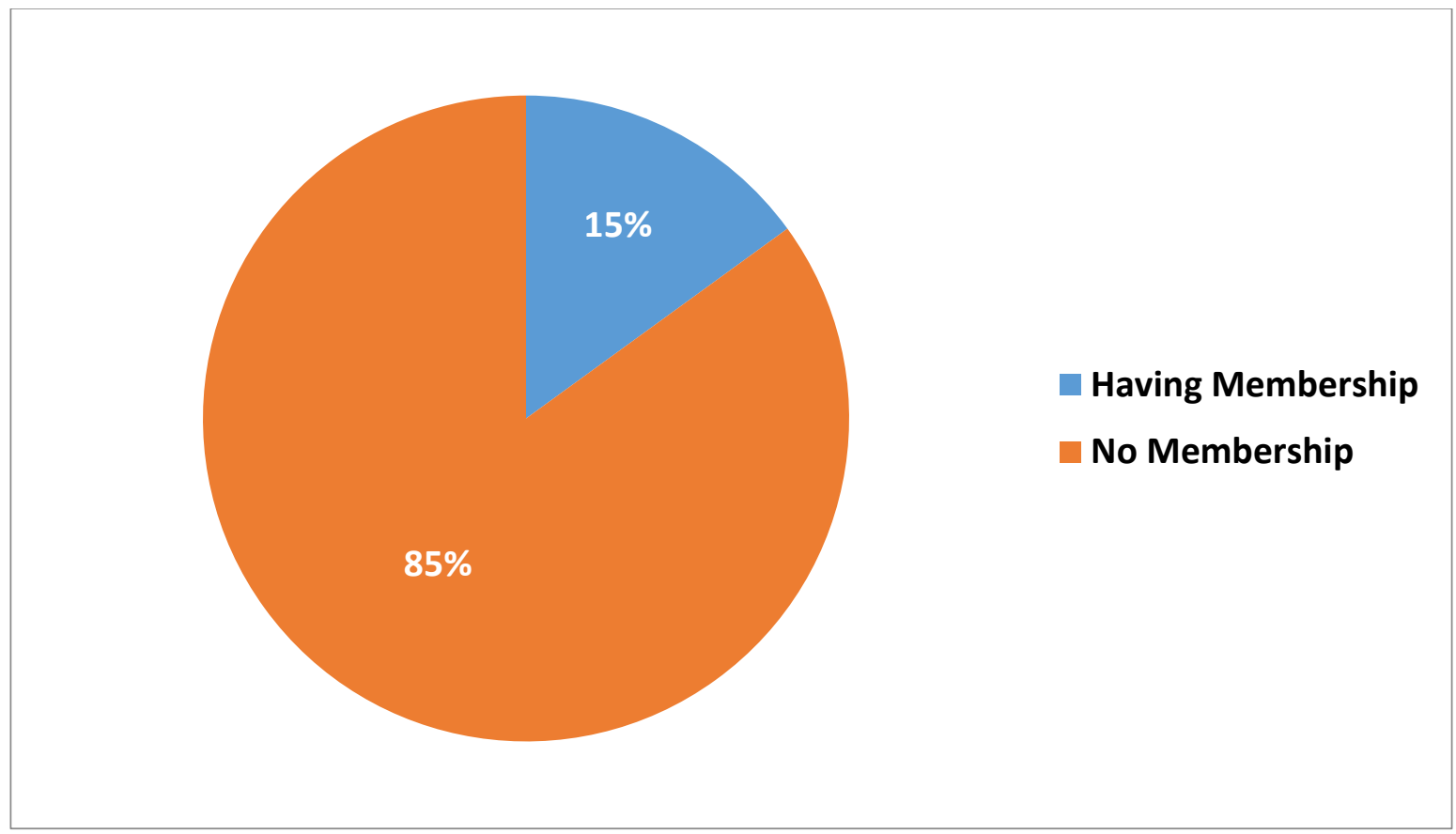

Graph 4.15 - \% of teachers having membership of e-library/e-journal/e-magazine

\section{ANALYSIS AND DISCUSSION:}

From the above data, it has been observed that-

- $\quad$ Percentage of teachers using online mode of teaching before COVID-19 is just $22 \%$ although $88 \%$ of the teachers are well acquainted to digital teaching techniques.

- $\quad$ Key barriers faced by teachers in offline education are query resolution, individual attention and lack of facility. Among which query resolution is the most prominent one as students of today's generation are having more knowledge due to online learning facility.

- Motivational factors influencing adoption of online education are home environment, convenience and reduced travel time, although home environment has maximum influence.

- $\quad$ The requirement to conduct online teaching are knowledge about ICT, Subject and Pedagogy but the foremost requirement is knowledge about ICT as without this knowledge about subject cannot be transfer to the students.

- $\quad$ Techniques used by teachers for interactive online teaching during lockdown are Google Classroom, Zoom Cloud \& Moodle Cloud among which Moodle cloud is being used maximum as teacher found it as the most convenient technique for online teaching.

- Being so convenient, students are not attending online mode of education due to the following factors like unfamiliarity of online education, internet connectivity, popularity of offline education. Among all the above factors, internet connectivity is the most influencing factor.

- $\quad$ Teachers are using online resources available like online books, you tube videos and online study material to prepare for online teaching as physical library facilities cannot be used at present due to lockdown.

- $\quad$ Online learning is most popular mode of learning in modern students as it is according to the students' interest and need.

- $\quad$ Only $63 \%$ of teachers have the knowledge about MOOC's and Digitally Robust Campus.

- Major problem associated with education during COVID-19 is conducting online exams i.e. $68 \%$ teachers have given this response.

- Hardly few teachers i.e. $15 \%$ have membership of e-library, e-journal, e-magazines.

\section{SUGGESTIONS}

- Government should organize short courses to train and prepare both teachers and students for online education.

- $\quad$ Government should take necessary step to standardized online teaching and learning process so that all learners will be benefitted by it uniformly.

- $\quad$ Government should allowed flexibility in curriculum to ease course burden for both teachers and learners.

- Government should also work on learner's oriented technology driven modification of syllabus. 
- $\quad$ Government should assure digital infrastructure for teach from home and learn from home to achieve desired learning outcomes.

- $\quad$ Arrangement of counselors for both teachers and learners should be arranged so that they can easily come out of the psychological issues like anxiety, depression, and frustration etc. arose due to COVID-19.

- Administrators should organize courses to make teachers well versed in advanced online teaching techniques.

- Administrators should motivate teachers for their efforts to organize online classes to solve student's queries.

- Irrespective of the problems associate with internet connectivity, students of rural areas should be provided with printed learning material so that they can't be left behind.

- $\quad$ College should stock digital learning material that can be used by both teachers and students without any physical barriers.

- $\quad$ Teachers and students should also be trained in online exam system so that, so its successful implementation can be achieved.

- $\quad$ Teachers should be provided with free membership of e-book, e-journals and e-magazines so that they can contribute to research work without any barriers.

- Teachers should practice interactive mode of online education to connect the students' emotionally i.e. cooperative learning, peer tutoring, multisensory approach etc. to develop better understanding and interest of learners towards learning.

- $\quad$ There should be proper communication between teachers and students for increasing the effectiveness of teachinglearning process.

- To make education system work efficiently, four A's should be remembered i.e. Availability; Accessibility; Acceptability; Adaptability.

- $\quad$ Students should try to attend classes organize by teachers to enrich their learning experience.

- $\quad$ Parents should keep an eye on their children so that they can be benefitted by the online classes organized for them.

\section{CONCLUSION}

Digital infrastructure plays a pivotal role in implementing online education successfully. Digital resources empower teacher and students for online teaching-learning process. Today's educational environment is dynamic and challenging, which demands the teachers to play a significant role to guide and motivate students in present crisis so that they do not get stress due to uncertainty of future. There is a need to bridge the gap between teachers and students through online education so that students can connect their teachers to fulfill their queries. Educational institutions and teachers have to take the responsibility to empower the young India and for that purpose both teachers and students need to acquire digital competencies to face the challenges in education during COVID-19 crisis.

\section{REFERENCES}

[1] Akkoyunlu, Buket, Yilmaz ; (2011); Prospective Teachers' Digital Empowerment and Their Information Literacy Self-Efficacy; Eurasian Journal of Educational Research (EJER) 11(44):33-50.

[2] Dua, Shikha; Wadhawan, Seema, Gupta, Sweety; (2016); Issues, Trends \& Challenges of Digital Education: An Empowerment Innovative Classroom Model for Learning www.conferenceworld.in, ISBN: 978-81-932074-8-2.

[3] Gowri, D. Pushpa, Suhas, U., (2017); A Study on the Influence of Digital Empowerment among Teachers in Contemporary Teaching, Research in Digital Revolution and New India (ISBN: 978-1-5136-2964-3)

[4] Shenoy Veena, Mahendher Sheetal, Vijay, Navita; (2020); COVID 19 Lockdown Technology Adaption, Teaching, Learning, Students Engagement and Faculty Experience; Mukt Shabd Journal, Volume IX, Issue IV, APRIL/2020, ISSN No : 2347-3150

[5] https://www.weforum.org/agenda/2020/04/digital-infrastructure-public-health-crisis-covid-19/

[6] www.online-education-in-india-2021.pdf

[7] https://www.cnbctv18.com/technology/digital-education-during-covid-19-lockdown-not-for-all-5785491.htm

[8] https://www.jisc.ac.uk/news/is-digital-technology-changing-learning-and-teaching-15-mar-2017.

[9] https://www.nie.edu.sg/teacher-education/useful-resources-for-HBL-WFH-EdCo/education-related-covid-19-articles

[10] https://www.nie.edu.sg/teacher-education/useful-resources-for-HBL-WFH-EdCo/education-related-covid-19-articles

[11] https://www.mygov.in/sites/default/files/user_submission/55aa0999e7f5443c6647dd5d7b347b5f.pdf 